INTRINSIC MOTIVATION AND WORK DEMANDS 1

\title{
Challenge and Hindrance Demands Lead to Employees' Health and Behaviors through Intrinsic Motivation
}

\author{
Minseo Kim and Terry A. Beehr \\ Department of Psychology \\ 101 Sloan Hall \\ Central Michigan University \\ Mount Pleasant, Michigan 48859, U.S.A.
}

Some of these data were presented at the $28^{\text {th }}$ Annual Convention of the Association for Psychological Science in Chicago, Illinois, USA.

\section{Author biographies}

Minseo Kim is an I/O Psychology $\mathrm{PhD}$ student at Central Michigan University. Her research inte rests include occupational stress, leadership, motivation, job crafting, careers, and employee well -being.

Minseo Kim is the corresponding author and can be contacted at: minseokim0331@gmail.com

Terry A. Beehr is a Professor of Psychology and member of the I/O Psychology faculty at Centr al Michigan University. His research interests include occupational stress, retirement, leadership, motivation, and careers. 
INTRINSIC MOTIVATION AND WORK DEMANDS 2

\begin{abstract}
Based on the Job Demand-Resource theory (J-DR), this study examined the differential relationships of two types of job demands, challenge and hindrance stressors, with three outcomes: ill health, organizational citizenship behavior, and work engagement. These relationships were mediated by two personal resources, psychological empowerment and organization-based self-esteem (OBSE). Data were collected at two separate points, two weeks apart. With 336 full-time US employees, results from path analysis indicated that the challenge stressor, workload, was positively related to psychological empowerment and OBSE, both of which were in turn positively related to good work behaviors as well as negatively related to ill health, an indication that employees experienced physical symptoms and psychological strains. In contrast, hindrance stressors (role stressors and interpersonal conflict) showed the opposite patterns of relationships with these intermediate outcomes, resulting in less empowerment and OBSE. Overall, findings suggested that psychological empowerment and OBSE were important intrinsic motivational mechanisms through which some stressors (especially hindrance demands) can promote employees' favorable work behaviors as well as alleviate the negative health outcomes.
\end{abstract}

Keywords: work demands; psychological empowerment; organization-based self-esteem; health; work behavior 
INTRINSIC MOTIVATION AND WORK DEMANDS 3

\section{Challenge and Hindrance Demands Lead to Employees' Health and Behaviors through Intrinsic Motivation}

Work stressors are demanding situations or characteristics in employees' jobs that can cause physical and psychological health problems (strains) and impede productive work-related behaviors (Beehr, 2014). The Job Demands-Resources model (JD-R theory; Bakker \& Demerouti, 2007) assumes that many employees have jobs involving health-impairing demands, but they also have some resources to help deal with demands and protect their well-being (Bakker \& Demerouti, 2014). Organizational researchers have distinguished between hindrance demands and challenge demands, showing that stressors sometimes differ in their effects (Cavanaugh, Boswell, Roehling, \& Boudreau, 2000; meta-analyses by LePine, Podsakoff, \& LePine, 2005; Podsakoff, LePine, \& LePine, 2007). We integrate JD-R theory with the challenge-hindrance framework to explain how personal resources are mechanisms transmitting effects of stressors to both employee health and work-related outcomes. The personal resources are forms of motivation: psychological empowerment and organization-based self-esteem (OBSE) (Figure 1). Personal resources, defined as individuals' characteristics reflecting their ability to control effectively and influence their environment successfully (Xanthopoulou, Bakker, \& Fischbach, 2013), provide the employee with confidence and intrinsic motivation to act on behalf of their organization. We chose these two personal resources because we intended to use personal resources that are relatively more motivational rather than other, more trait-like personal resources such as resilience and hardiness (Bakker \& Demerouti, 2014; King, King, Fairbank, Keane, \& Adams, 1998).

The challenge-hindrance stressor distinction was derived from the concepts of (1) stressor appraisal (Lazarus \& Folkman, 1984) and (2) eustress (Selye, 1974). Challenge stressors 


\section{INTRINSIC MOTIVATION AND WORK DEMANDS 4}

include the demands of workload or time pressure (e.g., LePine et al., 2005), demands that are challenging but can be overcome with enough skill and extra effort. Theoretically, this distinction is used to argue that overcoming challenge demands such as high workload necessarily means that employees have made a big achievement (completed a lot of work); if so, a sense of achievement could lead to some favorable outcomes for employees. Hindrance stressors are demands that thwart employees' progress toward normal work goal attainment; examples include role ambiguity and interpersonal conflict (e.g., Cavanaugh et al., 2000; Webster, Beehr, \& Love, 2011). Webster et al. (2011) argue that ambiguous tasks, for example, make it unclear how to direct one's efforts, and even if ambiguity is overcome, the efforts only lead to ordinary performance. Even though challenging demands can be related to strains, they are sometimes related to favorable outcomes such as work engagement, performance, and extra role behaviors (meta-analysis by LePine et al., 2005). As an explanation for this relationship, we propose that forms of intrinsic motivation — psychological empowerment and OBSE — as key resources in occupational stress (e.g., Hunter \& Wu, 2016) can mediate relationships of challenge and hindrance stressors with important outcomes. Psychological empowerment is a more job-related motivation (the job empowers employees; Conger \& Kanungo, 1988; Spreitzer, 1995; Thomas \& Velthouse, 1990), whereas OBSE is a more self-related motivation (a form of self-esteem; Pierce, Gardner, Cummings, \& Dunham, 1989).

The JD-R model and other resource theories of stress (e.g., conservation resources theory; Hobfoll, 1988) describe some personal resources as positive self-evaluations associated with resiliency and control (Bakker \& Demerouti, 2014) that can predict work engagement and positive affect (Tadić, Bakker, \& Oerlemans, 2015). By coping with challenge stressors, employees usually demonstrate their competence at high levels, which in turn leads to favorable 
self-evaluations, the essence of self-esteem (Widmer, Semmer, Kälin, Jacobshagen, \& Meier, 2012). Thus, we posit that employees' self-esteem may increase if challenging demands are overcome by effort. Psychological empowerment consists of meaning, self-determination, competence, and impact (Spreitzer, 1995), which are personal resources, because these factors enable empowered employees to effectively control their environments and be confident in their jobs. Conger and Kanungo (1988) and Thomas and Velthouse (1990) argued empowerment was a form of intrinsic motivation related to self-efficacy; it is an active orientation toward work, motivating employees through felt responsibility (Spreitzer, 1995).

We propose that motivational mechanisms act as resources, accounting for the positive effects of challenge stressors on employee outcomes. Challenge demands may actually increase some motivational resources by encouraging employees to believe in their abilities (such as OBSE) (similar to work self-efficacy in Webster, Beehr, \& Christiansen, 2010). Challenges highlighting the potential for personal growth should trigger positive affective responses and can link stressors to favorable outcomes (LePine et al., 2005; Podsakoff et al., 2007).

Challenging demands include the related stressors of time pressure and high workload, which should increase motivation by promoting opportunities for high goal attainment (Boswell, Olson-Buchanan, \& LePine, 2004). Because challenges often involve opportunities for learning and achievements, they may give employees a chance to experience meaningful work, intrinsic motivation, competence, and self-determination, which represent components of psychological empowerment (Spreitzer, 1995). We propose then that challenging job demands increase the intrinsic worth of accomplishing job purposes (Crawford, LePine, \& Rich, 2010), which fosters perceptions of psychological empowerment. Contrary to challenge stressors, hindrance stressors, which include role ambiguity, role conflict, and interpersonal conflict, are associated with lower 


\section{INTRINSIC MOTIVATION AND WORK DEMANDS 6}

levels of motivational resources. Furthermore, hindrance stressors do not inherently represent high goals as challenge stressors can, and therefore overcoming them is likely to result in merely acceptable rather than outstanding performance. Hindrances are also proposed to affect mediators, but in the opposite direction - they lead to less OBSE and empowerment.

Although little research has directly investigated the links between hindrance stressors and psychological empowerment, some research examined related variables. For example, hindrance stressors were negatively associated with work self-efficacy, which is similar to competence (Webster et al., 2010), and hindrance stressors were also related to reduced perceptions that jobs were meaningful, a facet of psychological empowerment (Spreitzer, 1995). Negative relationships between hindrance stressors and OBSE also may occur, because hindrances can interfere with successful job performance (Bowling, Eschleman, Wang, Kirkendall, \& Alarcon, 2010), which should result in decreased self-esteem. Regarding the hindrance stressor interpersonal conflict, it is argued "self-esteem finds its roots, in part, in messages of value transmitted from the organization to the employee via interpersonal relationships" (Pierce \& Gardner, 2004, p. 601). Thus, poor interpersonal relationships may result in lower OBSE. The first links in the model in Figure 1 hypothesize that:

Hypothesis 1. Challenge stressors (workload/time pressure) are positively related to (a) psychological empowerment and (b) OBSE.

Hypothesis 2. Hindrance stressors (role ambiguity/role conflict and interpersonal conflict) are negatively related to (a) psychological empowerment and (b) OBSE.

We examine three outcomes: employees' ill health (e.g., psychological strain and physical symptoms), organizational citizenship behaviors, and work engagement. Research on psychological empowerment has suggested some relationships between empowerment-related 


\section{INTRINSIC MOTIVATION AND WORK DEMANDS 7}

variables and employee health (Seibert et al., 2011; Spreitzer, Kizilos, \& Nason, 1997). Spreitzer et al. (1997) reported that self-determination, competence, and impact were related to lower levels of strain because they increased sense of control at work even when job demands increased. That is, parts of psychological empowerment were negatively related to both psychological and physical ill health indicators (Hochwälder \& Brucefors, 2005; Spreitzer et al., 1997); self-determination, another part of empowerment, was negatively related to emotional exhaustion and poor mental health outcomes (e.g., somatic symptoms, anxiety, and insomnia) (Hochwälder \& Brucefors, 2005).

We also propose that psychological empowerment should also be related to the workrelated outcomes in Figure 1, organizational citizenship behaviors (OCBs) and work engagement. Individuals who feel empowered are likely to perform beyond the minimum role requirement, engaging in OCBs to help their organization and their coworkers (meta-analysis by Seibert et al., 2011). Empirical findings support the above argument, showing that employees displayed OCB when they experienced meaningfulness, self-determination, competence, and impact (which are similar to empowerment;Macsinga, Sulea, Sârbescu, Fischmann, \& Dumitru, 2015).

Psychological empowerment also may result in employees' work engagement because of the responsibility and ownership empowered employees can feel. Again, studies of similar variables suggest this relationship. One study revealed that when employees have opportunities to feel meaningfulness in work, they show enthusiasm and willingness to invest themselves more in it, which results in more engagement (May, Gilson, \& Harter, 2004). Another study showed empowerment was a resource consisting of psychological, social, or organizational facets that are related to control, coping, autonomy, and decision-making resources that predict work 
engagement (Mauno, Kinnunen, \& Ruokolainen, 2007). Overall, although there is little direct research on the relationship between psychological empowerment and the specific outcomes in Figure 1, there is strong reason to predict it.

Hypothesis 3. Psychological empowerment is negatively related to (a) ill-health and positively related to (b) OCBs and (c) work engagement.

The other personal resource proposed as a mediator in Figure 1, OBSE, is also expected to have positive effects on mental and physical health, but little research attention has been given to these relationships. Employees with high self-esteem develop positive work attitudes and behavior towards the organization (meta-analysis by Bowling et al., 2010); therefore, they should be better able to overcome stressful conditions, showing more adaptive coping behaviors and seeking ways of enhancing their well-being. We posit therefore that OBSE is likely to help employees experience less psychological strain and physical health symptoms; in two studies, a positive self-concept (e.g., self-esteem and self-efficacy) was negatively related to depression and physical health problems (Karademas, Kafetsios, \& Sideridis, 2007; Lee, Joo, \& Choi, 2013).

Because OBSE is a motivational variable (Thomas \& Velthouse, 1990), it is also likely to influence employees' behavioral responses. Individuals have a basic need to enhance and protect positive aspects of their self-concept (Sedikides, Skowronski, \& Gaertner, 2004), which they should be able to do by exhibiting their competence as they engage fully in their regular tasks and OCBs. We expect high OBSE employees to help others and/or engage in behaviors benefiting their organization in order to maintain consistency between their self-views and their behaviors. There is some limited empirical support for this assertion. For example, employees who view themselves as organizationally valuable engaged in cooperative behaviors a form of 
OCB (Bowling et al., 2010; Pierce \& Gardner, 2004) and contextual performance (similar to OCBs; Aryee, Chu, Kim, \& Rhu, 2013).

Finally, OBSE is proposed to influence work engagement, because employees with high OBSE perceive their organization as important for satisfying their needs (Barbier, Hansez, Chmiel, \& Demerouti, 2013). Somewhat related empirical findings showed that OBSE was positively related to the employees' innovative behaviors, including generating creative ideas and developing plans (Chen \& Aryee, 2007). Taken together, we propose that employees' perceived value and competence within their organization will contribute to improving health, productive extra-role behaviors, and work engagement.

Hypothesis 4. OBSE is negatively related to (a) ill-health and positively related to (b) OCBs and (c) work engagement.

\section{Mediation}

Although each link in the model in Figure 1 represents a separate hypothesis, the model inherently proposes mediation. The two mediators, psychological empowerment and OBSE, are proposed as explanations for the effects of challenge and hindrance demands on the three outcomes, and we therefore tested for evidence of the following types of mediation:

(1) Psychological empowerment mediates the link of challenge stressors with the illhealth, OCBs, and work engagement.

(2) Psychological empowerment mediates the link of hindrance stressors with the illhealth, OCBs, and work engagement.

(3) OBSE mediates the link of challenge stressors with the ill-health, OCBs, and work engagement. 
(4) OBSE mediates the link of hindrance stressors with the ill-health, OCBs, and work engagement.

To allow changes in employees' motivational states (two mediators) in responding to the two work stressors, we employed a time lag of two weeks between measurements.

By applying the challenge-hindrance distinction to stressful job demands, the study contributes to occupational stress knowledge by specifying resources related to these demands. It builds on the JD-R model by proposing some types of demands can lead to resource loss but other types of demands can lead to resource gain, and these resources are mediators between stressors and outcomes. By integrating the stress and motivation literatures, we developed a theoretical model linking employees' stressors to work-related outcomes and health through the effects of two personal resources. This is a response to the call for research (Rubino, Luksyte, Perry, \& Volpone, 2009; Webster et al., 2011) to examine the intermediate processes explaining how hindrance and challenge demands may differentially affect employees and their work. We thus contribute a theoretical explanation for why different types of work demand characteristics or stressors can induce different responses in employees, integrating JD-R theory with the concepts of challenge and hindrance demands.

\section{Methods}

\section{Participants and Procedure}

Data were collected at two time points, with a 2-week lag, through Mechanical Turk (MTurk), a commercial service that pays respondents for participating in surveys, providing participants from a broad range of employees, jobs, and geographic locations. We needed to choose a time interval that allows changes in employee's motivational states (psychological empowerment and OBSE) in responding to the work stressors. We chose two weeks, because 
INTRINSIC MOTIVATION AND WORK DEMANDS 11

some previous studies of occupational stress have successfully employed a time lag of two weeks between measurements of similar variables in the stress domain (e.g., Fodor, Antoni, Wiedemann, \& Burkert, 2014; Fritz \& Sonnentag, 2006).

Recent studies suggested that MTurk workers tend to carefully read survey instructions and be representative of US population characteristics in terms of age, ethnicity, education, and work experience, even providing higher-quality data that are comparable to those from some other data sources (Goodman, Cryder, \& Cheema, 2013; Ramsey, Thompson, McKenzie, \& Rosenbaum, 2016). We required respondents to be full-time (working 30 hours or more per week) employed adults aged 18 and older, working in the US, and holding a 95\% approval rating from previous MTurk assignments, consistent with existing recommendations (e.g., Mason \& Suri, 2012). Furthermore, we used several procedures in order to control the quality of the data (Cheung, Burns, Sinclair, \& Sliter, 2017; DeSimone, Harms, \& DeSimone, 2015). First, we blocked IP addresses after completion of the survey, preventing multiple completion attempts of participants. Second, we included reverse-worded items; if participants provided the same answers across the reversed and non-reversed items, it meant they did not read survey items carefully. Finally, we eliminated cases with apparently low effortful responding; participants who selected many of the same responses (75\%) and completed the survey more than twice as fast as the average time were removed.

Initially, 784 employees completed the Time 1 survey. Of these, 355 employees responded at Time 2. Among them, the data for 19 were dropped due to low effort responding and/or unmatched codes from Time 1 and Time 2. The hypotheses were tested with a final sample of 336 responses: $55.5 \%$ were female $80.7 \%$ white $(8.6 \%$ African-American, $6.5 \%$ Asian/Asian-American, 3.0\% Multi-racial, and 1.2\% other), and 70.2 \% had at least a bachelor's 
degree ( $9 \%$ had high school degrees and $20.8 \%$ two years of college). Participants were employed in a variety of industries (e.g., education, health-care, retail, and technology), and 44.4\% had entry-level jobs, $7.7 \%$ executive-level, $3.9 \%$ senior management, $3.6 \%$ middle management, $39.9 \%$ other, and $0.5 \%$ did not report their job levels. The sample consisted of somewhat young employees, as $64.2 \%$ were between 18 and 39 years old, $17.3 \%$ between 40 and $49,13.4 \%$ between 50 and 59 , and $5.1 \%$ were more than 60 years old.

\section{Measures}

Measures administered at different times reduce the possible effects of common method variance on the relationships among the variables (Podsakoff, MacKenzie, \& Podsakoff, 2012). Both demands, the challenge and hindrance stressors, were measured at Time 1, the outcomes were measured at Time 2, and the mediators (resources) were measured at both Time 1 and Time 2. Table 1 contains the reliabilities of the all measures.

Challenge stressors at Time 1. Workload was assessed using three items from the Quantitative Workload Inventory (QWI; Spector \& Jex, 1998) and four items from the Time Pressure Scale (Kinicki \& Vecchio, 1994). The original Workload Scale had five items, but two of them referred directly to time pressure, which overlapped with the wording of the time pressure scale. Therefore, they were not used in the workload measure. An example item for workload is "How often do you have to do more work than you can do well?" rated on a 5-point scale from 1 (less than once per month) to 5 (several times per day). Internal consistency reliability for the whole 5-item scale was reported by Spector and Jex (1998) to average .82 across 15 studies. Validity evidence presented in Spector and Jex (1998) showed that the $Q W I$ was positively related to job performance and negatively related to job satisfaction. 
An example item for time pressure is "I have to rush in order to complete my job" rated on a 5-point frequency scale from 1 (never) to 5 (always). Previous research reported a favorable reliability estimate (alpha $=.77$ ) for the 4-item Time Pressure Scale, which was a subscale Matteson and Ivancevich's (1987) Stress Diagnostic Survey. It showed predictive validity by its positive correlation to the quality of supervisor-subordinate relations (Kinicki \& Vecchio, 1994).

Hindrance stressors at Time 1. Role stressors were measured using the role ambiguity and role conflict scales from Rizzo, House, and Lirtzman (1970). An example role ambiguity item is "I know exactly what is expected of me" (reverse-scored). Role conflict was measured with eight items. An example item is "I receive incompatible requests from two or more people." Respondents rated each item on a 7-point scale ranging from 1 (strongly disagree) to 7 (strongly agree). Reliability coefficients have yielded acceptable alpha levels for both role ambiguity and role conflict, $\alpha=.78$ and $\alpha=.82$ respectively, with a 199-employee sample of central office and main plant personnel (Rizzo et al., 1970). The measures were shown to have positive relationship with emotional exhaustion, job dissatisfaction, and turnover intentions (Webster et al., 2011).

Interpersonal conflict was measured using the four-item scale from Spector and Jex's (1998) Interpersonal Conflict at Work Scale (ICAWS). An example item is "How often do you get into arguments with others at work?" rated on a 5-point frequency scale from 1 (never) to 5 (always), with high scores indicating a high degree of interpersonal conflict. Spector and Jex (1998) reported a reliability of .74 and found this measure to be related to psychological strain (e.g., frustration and depression) and poor performance.

Mediators at Time 1 1 $1 / 2$. Only the two mediators, the motivational resources, were measured at both time points. Note that the mediators are state-like (i.e., changeable) and not trait-like (stable), because they (and the criterion variables in the model) are endogenous and are 
theoretically caused by the variables preceding them (left of them in the model). Thus, the mediators' scores would change from one situation to another (in the model in Figure 1, from one level of the stressors to another). We used the midpoint estimation technique to assign mediator scores (Kim \& Beehr, 2017). This approach uses the mean of employees' Time 1 and Time 2 scores as an estimate of their score between the two time points (referred to subsequently as Time $1 \frac{1 / 2}{2}$ ). We cannot know the employees' scores at the exact midpoint of the study, but this use of the mean scores from the two time periods is based on the rationale that if a variable has different values initially from its value two weeks later, its value at some time between these two time periods was highly likely to be between its values at the start and end of the study period. Importantly, we support this assumption below with statistical evidence demonstrating that participants' scores on the mediators did change significantly between Times 1 and 2, thereby suggesting that the mean between the two measurements captures people's scores at some point between Times 1 and 2 .

Psychological empowerment was assessed with Spreitzer's (1995) twelve-item Empowerment Scale. Example items of the four dimensions include "My job activities are personally meaningful to me" (meaning), "I am confident about my ability to do my job" (competence), "I have significant autonomy in determining how I do my job" (selfdetermination), and "I have a great deal of control over what happens in my department" (impact). Respondents rated items on a 7-point Likert scale ranging from 1 (strongly disagree) to 7 (strongly agree). Internal consistency reliability for the overall empowerment construct was $\alpha$ $=.62$ for an insurance sample and $\alpha=.72$ for an industrial sample (Spreitzer, 1995). Also, the four dimensions of psychological empowerment were found to be positively correlated with each other in both samples and shown to have significant relationships with self-esteem, managerial 
effectiveness, and innovative behavior, demonstrating predictive validity (Spreitzer, 1995). The mean absolute difference in psychological empowerment from T1 to T2 was 0.74 with a standard deviation of 0.53 , indicating that many employees' scores had changed during this two-week interval. A one-sample $t$-test showed that the average change was significant, $t(335)=25.57, p$ $<.01$. Therefore, the mean of $\mathrm{T} 1$ and $\mathrm{T} 2$ estimated the score between $\mathrm{T} 1$ and $\mathrm{T} 2$.

Organization-based self-esteem (OBSE) was measured with the ten items developed by Pierce et al. (1989). An example item is "I am valuable in this organization" rated on a 7-point Likert scale from 1 (strongly disagree) to 7 (strongly agree). Pierce et al. (1989) reported an alpha of .91 and the test-retest reliability coefficient of .75. They found this measure to be positively related to several criteria including work motivation, job satisfaction, organizational commitment, and performance, which provided evidence of predictive validity (Pierce et al., 1989). The mean absolute difference in OBSE from T1 to T2 was 0.64 with a standard deviation of 0.57 , indicating that many employees' scores had changed during this two-week interval. A one-sample $t$-test showed that the average change was significant, $t(335)=20.48, p<.01$. Therefore, the mean of T1 and T2 estimated the score between T1 and T2.

Outcome measures at Time 2. Two aspects of employee health were measured: physical ill health and psychological strain. To measure physical ill health, respondents completed a 12- item version of the Physical Symptoms Inventory (PSI: Yang, Spector, GallantRoman, \& Powell, 2012) developed by Spector and Jex (1998). An example item is "How often have you experienced headaches?" over the past month, rated on a 5-point scale from 1 (not at all) to 5 (every day). Reliability estimates for it have been acceptable (alpha $=.89$; Webster et al., 2010), and it has been shown to be related to several job stressors such as quantitative workload, role conflict, and interpersonal conflict (reported in Spector \& Jex, 1998). 
Psychological strain was measured with a 12-item version of the General Health Questionnaire (GHQ-12, Goldberg, 1972). An example item is "Have you recently been feeling unhappy or depressed?" rated on a 5-point scale from 1 (not at all) to 5 (all of the time). The General Health Questionnaire $(G H Q)$ has been validated in many different populations. The English version $G H Q-12$ yielded a Cronbachs alpha of .90 and a split half reliability of .91 (Jacob, Bhugra, \& Mann, 1997), and it was related to job characteristics including autonomy, job insecurity, and work demands (Witte, 1999).

Organizational citizenship behaviors (OCBs) were measured with the fourteen-item scale from Williams and Anderson (1991). Seven items were directed at individuals (OCB-I) and seven at the organization (OCB-O). Respondents indicated the extent to which they engage in certain activities, using a 7-point Likert scale from 1 (strongly disagree) to 7 (strongly agree). Example items for OCB-I and OCB-O include "I help others who have heavy workloads" and "I conserve and protect organizational property." The original scale development study reported alphas of .88 for OCB-I and .75 for OCB-O, and both types of OCBs were associated with employee commitment, intrinsic and extrinsic cognitions, and positive arousal (Williams \& Anderson, 1991).

Work engagement was assessed using the seventeen items from Schaufeli and Bakker's (2003) Utrecht Work Engagement Survey (UWES). An example item is "I am enthusiastic about my job" rated on a 7-point scale ranging from 1 (never) to 7 (always). Schaufeli and Bakker (2003) reported that Cronbachs $\alpha$ of the total score for the 17-item UWES was .93. Previous research using this measure provided validity evidence showing its relationships with task, social, and personal resources (Weigl, Hornung, Parker, Petru, Glaser, \& Angerer, 2010). 
Demographic data (e.g., age, gender, college degree, and tenure) were measured as potential control variables because they might affect employee perceptions of the stressors, motivation, and behaviors. However, these factors did not significantly influence the conclusions in the present study: Gender was related only to OCBs $(r=.18, p<.01)$; college degree to role stressors $(r=.11, p<.05)$; tenure to psychological empowerment $(r=.17, p<.01)$; age to psychological empowerment $(r=.12, p<.05)$, OCBs $(r=.11, p<.05)$, and work engagement $(r$ $=.12, p<.05)$. Therefore, the analyses with control variables were not included in the results section in order to simplify reporting.

Combining measures. We conducted an overall measurement model, but first preliminary confirmatory factor analyses (CFA) were conducted for sets of variables where there were specific issues regarding convergence or differentiation. The choice of combining some variables was made in order to make the model more parsimonious where we could, avoid redundant analyses (especially for criterion variables such as health), reduce the potential for multicollinearity to affect results (especially for predictor variables like the stressors), and save degrees of freedom.

Some of the predictors (stressors) measured at $\mathrm{T} 1$ were conceptually similar to each other. First, workload and time pressure demands both are concerned with the amount of work one can do in the time available, because time and quantity of work jointly determine ability to perform the work; with more time, one can do more work, that is, a workload would not be high if there were more time. Therefore, we examined the possibility of combining workload and time pressure into one predictor variable via confirmatory factor analysis (CFA with LISREL 8.8 (Jöreskog \& Sörbom, 2006; which was used to obtain all model fit and parameter statistics in the study)). Second, the two role stressors, role ambiguity and role conflict, both are types of 
stressors that are due to role expectations and sent messages from other people in one's role set (e.g., Kahn, Wolfe, Quinn, Snoek, \& Rosenthal, 1964). Therefore, we also examined the viability of combining them into a single role stressor variable. Reducing the number of stressors from five to three would have the advantage of proposing and testing a more parsimonious model.

For CFAs focused on the predictor variable set (stressors), a five-factor and a three-factor model (workload/time pressure, the two role stressors, and interpersonal conflict) were tested. Workload and time pressure were indicators of one latent factor, role ambiguity and role conflict were indicators for the second factor, and the four items of interpersonal conflict were parceled into two indicators consisting of two items each in order to test the three-factor model. For the CFA, the standardized estimate of time pressure was greater than 1.00 . Thus, the four items of time pressure were parceled into two indicators. The three-factor model showed better fit on all indices, $\chi^{2}(11, N=336)=62.26, p<.01 ; \mathrm{SRMR}=.05 ; \mathrm{CFI}=.97 ; \mathrm{IFI}=.97 ; \mathrm{NNFI}=.94$ than the five-factor model $\chi^{2}(34, N=336)=240.91, p<.01 ; \mathrm{SRMR}=.09 ; \mathrm{CFI}=.94 ; \mathrm{IFI}=.94$; NNFI $=.90$. Therefore, three stressors (labeled workload, role stressors, and interpersonal conflict) were used for hypothesis testing (Figure 2).

For the criterion variable set, a main concern was the extent to which to the health scales (the PSI and the GHQ) were measuring the same construct. A four-factor measurement model focused on the criteria, $\chi^{2}(38, N=336)=203.84, p<.01 ; \mathrm{SRMR}=.07 ; \mathrm{CFI}=.95 ; \mathrm{IFI}=.95$; $\mathrm{NNFI}=.93$, including the two health variables as separate factors was compared to a three-factor model with them combined. In the three-factor model, physical symptoms and psychological strain were used as two indicators for one latent factor representing employee ill health. For the other two criterion variables, OCBs and work engagement, each of their subscales was used as an indicator: OCB-I and OCB-O for OCBs, and vigor, dedication, and absorption for work 
engagement. Most fit indices improved in the three-factor model, $\chi^{2}(11, N=336)=80.24, p$ $<.01 ; \mathrm{SRMR}=.05 ; \mathrm{CFI}=.96 ; \mathrm{IFI}=.96 ; \mathrm{NNFI}=.92$. Thus, physical symptoms and psychological strain measures were merged to a single variable for analysis.

Finally, because the two mediator variables, the resources of psychological empowerment and OBSE, were both conceived as forms of intrinsic motivation and were highly correlated $(r$ $=.83, p<.01)$, a CFA focused on them was also run to test the fit of a two-factor model for these measures. For psychological empowerment, its four dimensions served as indicators. For OBSE, the ten items were parceled to create three indicators (two consisting of three items each and one of four items). The two-factor model produced an acceptable fit, $\chi^{2}(13, N=336)=138.94, p$ $<.01 ; \mathrm{SRMR}=.06 ; \mathrm{CFI}=.95 ; \mathrm{IFI}=.95 ; \mathrm{NNFI}=.91$, the one-factor model $\chi^{2}(14, N=336)=$ $144.84, p<.01 ; \mathrm{SRMR}=.06 ; \mathrm{CFI}=.94 ; \mathrm{IFI}=.94 ; \mathrm{NNFI}=.91$, was not better, and therefore we retained the two mediators because they were originally hypothesized in the model.

Overall measurement model. We also tested the final overall measurement model (including all measures - three predictors, two mediators, and three outcomes - in one CFA). The results revealed the eight constructs used in the present study (Figure 2) to be distinct, $\chi^{2}(161, N=336)=928.90, p<.01 ; \mathrm{SRMR}=.08 ; \mathrm{CFI}=.94 ; \mathrm{IFI}=.94 ; \mathrm{NNFI}=.92$.

\section{Results}

Table 1 presents means, standard deviations, reliabilities, and correlations.

\section{Hypotheses and Model Testing}

The model was tested allowing errors of the two mediators to covary, and the hypothesized model fit the data well, $\chi^{2}(12, N=336)=78.63, p<.01$; SRMR $=.06$; CFI $=.96$; $\mathrm{IFI}=.96 ; \mathrm{GFI}=.94$. Workload as a challenge stressor was positively related to both mediators, 
psychological empowerment $(\beta=.14, p<.01)$ and OBSE $(\beta=.20, p<.01)$, supporting hypothesis 1 regarding the challenge stressor (Figure 2).

The results mostly supported hypothesis 2 . Three of the four paths from hindrances to the mediators were significant: role stressors to psychological empowerment $(\beta=-.52, p<.01)$ and OBSE $(\beta=-.54, p<.01)$, and interpersonal conflict to OBSE $(\beta=-.14, p<.01)$. Hypotheses 3 and 4 were also mostly supported, because five of the six paths from the mediators to the outcomes were significant: Psychological empowerment to ill health $(\beta=-.21, p<.05)$ and work engagement $(\beta=.47, p<.01)$; OBSE to ill health $(\beta=-.31, p<.01)$, OCBs $(\beta=.45, p<.01)$, and work engagement $(\beta=.29, p<.01)$.

We used the midpoint estimation technique (Kim \& Beehr, 2017) for measuring the mediating variables, because there was no logical or theoretical reason to choose a mediation score from either time 1 or time 2 alone, but as a check we analyzed the model twice more, once using the time 1 mediator scores and once using the time 2 mediator scores. Using time 1 mediator scores, fit statistics were somewhat worse than our original planned analysis, $\chi^{2}(12, N=$ $336)=129.88, p<.01 ; \mathrm{SRMR}=.08 ; \mathrm{CFI}=.92 ; \mathrm{IFI}=.93 ; \mathrm{GFI}=.91 . \mathrm{In}$ addition, the path from organizational psychological empowerment to OCBs became significant but the path from interpersonal conflict to OBSE was not significant. Using time 2 mediator scores, fit statistics were slightly better than our original analysis, $\chi^{2}(12, N=336)=74.81, p<.01$; SRMR $=.06$; $\mathrm{CFI}=.96 ; \mathrm{IFI}=.97 ; \mathrm{GFI}=.95$, and the path from interpersonal conflict to psychological empowerment became significant.

Finally, we also examined a model with role conflict and role ambiguity as separate variables instead of combining them into a single role stress variable, even though the CFAs had confirmed them as a single factor. The fit was slightly better than our original model, by .01 for 
CFI, IFI, and GFI, $\chi^{2}(15, N=336)=83.05, p<.01 ; \mathrm{SRMR}=.06 ; \mathrm{CFI}=.97$;FI $=.97$; GFI $=.95$. All paths for this model were significant except the path from the challenge stressor, workload, to one of the mediators, psychological empowerment. Overall, testing the model with slightly different constructions of the variables produced largely similar results.

\section{Mediation: Alternative Models}

The first way of testing mediation was to examine alternative models with direct paths from the stressors to the outcomes. Adding nine direct paths from the three stressors to the three outcomes provided improvement in some fit indices, $\Delta \chi^{2}(9, N=336)=39.37, p<.01, \Delta \mathrm{SRMR}$ $=.03, \Delta \mathrm{CFI}=.02$, suggesting that direct effects along with the indirect effects. Workload showed a direct relationship with work engagement $(\beta=.13, p<.01)$, and role stressors $(\beta=.14, p$ $<.01)$ and interpersonal conflict $(\beta=.16, p<.01)$ had direct relationships with ill health. Although the alternative model improved some fit indices, the effects were small; only three of the possible nine direct effects were significant, providing some support for mediation.

\section{Mediation: Bootstrapping}

Bootstrapping was calculated using the PROCESS macro (Hayes, 2013). Psychological empowerment and OBSE significantly mediated the relationships of hindrance demands (role stressors and interpersonal conflict) with ill health, OCBs, and work engagement, because their confidence intervals did not include a zero (Table 2). Hindrance stressors also had a direct effect on ill health but not on the other two outcomes. Most of the indirect effect sizes for the relations between hindrance stressors and the three outcomes were large, ranging from $k^{2}=.13$ to $k^{2}=.40$ (Preacher \& Kelly, 2011). In contrast, bootstrapping did not find mediation effects for the challenge demands. Overall, the fit statistics for the alternative model supported the model's 
mediation effects, but the bootstrapping results support mediation only for hindrance stressor effects being mediated.

\section{Discussion}

Psychological empowerment and OBSE are intrinsic motivational constructs that help explain the potential effects of work stressors on important outcomes. Overall, results supported most expectations that challenge stressors are positively and hindrance stressors are negatively related to psychological empowerment and OBSE, both of which may lead to desired consequences that benefit employees and their organizations. The direction of the significant findings supported the central tenets of the JD-R theory (Bakker and Demerouti, 2014); hindrance stressors as indicators of job demands may deplete employees' motivational energy, whereas challenge stressors may demand energy but also may increase motivational resources because they stimulate goal attainment and need satisfaction, thereby increasing employees' functioning (Schaufeli \& Taris, 2014).

Relationships between Stressors and Intrinsic Motivation (Psychological Empowerment and $O B S E)$

Although the relationships for the challenge stressor were somewhat weak, consistent with the challenge-hindrance framework (Cavanaugh et al., 2000; LePine et al., 2005), the challenge stressor, workload demand, predicted both psychological empowerment and OBSE, suggesting resource gain. We interpret this as due to challenge stressors, such as time pressure and workload, giving organizational members opportunities to recognize their competence and self-worth in challenging tasks; completion of these tasks represents high achievement (i.e., completing high workload). Hindrance stressors - role stressors and interpersonal conflict-were mostly negatively associated with subsequent psychological empowerment and OBSE, 
representing resource loss. Employees experiencing ambiguity and conflict about their roles feel both less psychological empowerment and OBSE, because hindrance stressors interfere with individuals' beliefs that they are able to meet job demands, and even if they do, this would not be seen as exceptionally high performance (as argued by Webster et al., 2010).

However, experiencing interpersonal conflict at work was not related to one mediator, feelings of psychological empowerment. Regarding hindrance stressors, feelings of psychological empowerment seems to be more affected by role stressors than interpersonal stressors. Negative relationships between hindrance stressors and OBSE were consistently evident however, supporting the assumption that hindrances potentially prevent employees from feeling competent, able, and successful (Bowling et al., 2010).

\section{Relationships between Intrinsic Motivation and Outcomes}

Based on JD-R theory, we predicted that the two motivational resources in the center of the model would be associated negatively with ill health and positively with work behaviors. The study found that both psychological empowerment and OBSE may play a role in individuals' success in overcoming physical symptoms and psychological strain, consistent with a few previous studies showing that psychologically empowered employees experienced less ill health (Hochwälder \& Brucefors, 2005; Seibert et al., 2011). We proposed that the control, capability, and meaningfulness in psychological empowerment and OBSE make employees likely to adopt active coping.

Regarding more behavioral outcomes, both psychological empowerment and OBSE were important factors predicting employees' work engagement, with OBSE also predicting OCBs. There were especially strong relationships of psychological empowerment with work engagement, and of OBSE with OCBs. The fact that psychological empowerment was closely 
related to work engagement was also found in Macsinga et al. (2015), but we failed to replicate outcomes of a previous research finding that empowerment is related to OCBs (Macsinga et al., 2015; Seibert et al., 2011). This could have been because we examined the unique and joint effects of both empowerment and OBSE, while the previous studies only examined empowerment. Employees with high OBSE, however, did display high levels of OCBs (consistent with the meta-analysis by Bowling et al., 2010; and OBSE was related to contextual performance in Aryee et al., 2013). We suggest that employees are motivated to maintain or increase positive aspects of their self-concept by engaging in these positive discretionary behaviors.

\section{Intrinsic Motivation Explains Differential Effects of Challenges and Hindrances}

Psychological empowerment and OBSE explained much of the link of the work stressors with subsequent outcomes. Employees who experience challenging workload and time pressure can be somewhat more intrinsically motivated because of feelings such as high competence. On the other hand, role stressors and interpersonal conflict, reflecting hindrance demands, may diminish intrinsic motivation, because it is hard to know how to succeed under these conditions. Therefore, empowerment and OBSE were crucial states explaining how challenge and hindrance stressors may have differential effects on subsequent individual and work-related outcomes.

\section{Contribution}

The results supported the usefulness of distinguishing between challenge and hindrance stressors, because they can be at least somewhat differentially related to intrinsic motivational resources operating as mediators between demands and outcomes in the JD-R theory. Hindrance stressors can lead to resource loss, but challenge stressors can potentially lead to resource gain. The results suggest a revision to JD-R theory in which, although the stressors or demands tend to 
INTRINSIC MOTIVATION AND WORK DEMANDS 25

deplete energy, at least some demands may also influence specific resources for the better, and intrinsic motivational mechanisms help to explain this process. The differential effects may be modest, however, because the path coefficients leading from the stressors to the resources were somewhat weak except for the role stressors. Nevertheless, it is notable that the paths from the challenge stressor to resources were positive, but the paths from the hindrance stressors were negative.

Although research has explored relationships between stressors and work-related outcomes, psychological empowerment and OBSE have been absent from consideration as explanations for these effects. Enhanced intrinsic motivation of employees through psychological empowerment and OBSE is likely to be an effective means for both promoting desirable behaviors and minimizing health problems. These results, therefore, contribute to the literature on the challenge-hindrance and JD-R frameworks by showing the importance of motivational resources in explaining differential effects of the two types of demands (challenges and hindrances) on important outcomes. In line with the JD-R theory amended by consideration of the challenge-hindrance distinction, although job demands may negatively influence outcomes, those job demands perceived as challenges could also function as a motivation-promoting resource. More specifically, employees working in a psychologically resourceful environment feel more able to perform their tasks without excessive efforts, and as a result, they are not as vulnerable to ill health or health-related productivity losses that can be due to stress (e.g., consistent with conclusions from Bakker \& Demerouti, 2014).

We also added contextual performance (OCBs) as a consequence of job resources and demands, unlike previous studies focusing on work engagement and well-being (e.g., burnout). By suggesting the motivational role of personal resources in predicting positive outcomes and of 
INTRINSIC MOTIVATION AND WORK DEMANDS 26

high challenge demands potentially enhancing some resources, we showed that the positive effects of challenge stressors might include both good health and good organizational outcomes.

\section{Practical Implications}

Employees' desirable responses in terms of OCBs and engagement could be promoted if perceived challenge demands and personal resources are increased. On the other hand, hindrance demands and poor resources may only foster physical and psychological costs; hindrance stressors had direct as well as indirect effects on health outcomes in the present study. Therefore, employees' well-being and favorable behaviors may be improved by managers' attempts to decrease hindrances that entail loss in resources, such as role stressors. The transactional stress model (Lazarus and Folkman, 1984) from which the challenge-hindrance framework is derived, maintains that if individuals perceive that their resources can compensate for the environmental demands (allowing successful coping), their response to the stressors could be more positive.

Interpersonal conflict, a hindrance demand, negatively predicted employees' evaluation of their worthiness as an organizational member. One means to alleviate this problem would be relationship conflict management training to help employees build or preserve personal resources. In addition, supervisors may be important in mitigating interpersonal conflict; helpful and concerned acts by supervisors act as a buffer for the negative consequences of conflict (Ilies, Johnson, Judge, \& Keeney, 2011). Lastly, job characteristics may be hard to change whereas interventions to develop employees' personal resources may require less effort. Research has already demonstrated the viability of interventions in cultivating employees' psychological resources (e.g., confidence/efficacy) (Luthans, Avey, Avolio, Norman, \& Combs, 2006). Overall, findings highlighted that personal resources are probably as important as the job resources that are more commonly studied (e.g., coaching, performance feedback, and job control). 


\section{Limitations and Directions for Future Research}

The study utilized cross-time data consistent with causal inferences regarding the relations between predictors, mediators, and outcomes. Nevertheless, even stronger causal inferences would be warranted with an experimental or quasi-experimental design, which allows for controlling one set of the variables and manipulating the others (Cook \& Campbell, 1979). Due to the random assignment and a controlled environment of a true experiment, more confidence in internal validity could be gained.

Another potential method limitation is the possibility of same-source bias. Key variables were measured at different points in time, however, which helps reduce this problem (Podsakoff, et al., 2012). In future studies, ratings of behavioral outcomes such as OCBs could be assessed by managers or coworkers. On the other hand, some constructs such as psychological empowerment and OBSE, as well as psychological and physical health, deal with individual's inner states and reactions. For these, it may be more accurate to obtain the data from respondents themselves.

The challenge-hindrance model is based on the principle of appraisal, derived from transactional stress theory (Lazarus \& Folkman, 1984). That is, it assumes that individuals' appraisals of demands as challenging or hindering are necessary for the demands to have their specific effects on the person. In the challenge-hindrance research in the workplace, these individual appraisals are not usually measured; instead, as in the present study, researchers assign demands to the challenge and hindrance categories based on logic and some past research that had participants or others assess appraisals as challenges and hindrances (e.g., Cavanaugh et al., 2000; Webster, Beehr, \& Love, 2011). Because the present study did not measure individual appraisals directly, differential results for these two types of stressors were likely diminished. 
Aside from method limitations, the stressors studied were only a subset of challenge and hindrance stressors. Reviews have not identified very many other challenge demands (responsibility is one; Webster et al., 2011), but other hindrance demands include work constraints, hassles, and resource inadequacy for example (e.g., LePine et al., 2005; Podsakoff et al., 2007). This also suggests that theory and research could ask and examine whether there are actually more types of hindrance demands than challenge demands.

\section{Conclusion}

This study explains the potentially differential effects of challenge and hindrance stressors on individual and organizational outcomes by examining two motivational resources based on JD-R theory. Challenge demands are more likely to help improve motivational states and thereby increase desirable work behaviors and reduce aversive health effects; these effects were somewhat weak, however. Hindrance demands, in contrast, are more likely to reduce motivation and thereby inhibit desirable work behaviors, while also harming the individual. 
INTRINSIC MOTIVATION AND WORK DEMANDS 29

\section{References}

Aryee, S., Chu, C. W., Kim, T. Y., \& Rhu, S. (2013). Family-supportive work environment and employee work behaviors: an investigation of mediating mechanisms. Journal of Management, 39, 792-813.

Bakker, A.B., \& Demerouti, E. (2007). The Job Demands-Resources model: State of the art. Journal of Managerial Psychology, 22, 309-328.

Bakker, A. B., \& Demerouti, E. (2014). Job demands-resources theory. In C. Cooper, \& P. Chen (Eds.), Wellbeing: A complete reference guide. Chichester: Wiley-Blackwell.

Barbier, M., Hansez, I., Chmiel, N., \& Demerouti, E. (2013). Performance expectations, personal resources, and job resources: How do they predict work engagement? European Journal of Work and Organizational Psychology, 22, 750-762.

Beehr, T. A. (2014). Psychological stress in the workplace (psychology revivals). New York: Routledge.

Boswell, W. R., Olson-Buchanan, J. B., \& LePine, M. A. (2004). Relations between stress and work outcomes: The role of felt challenge, job control, and psychological strain. Journal of Vocational Behavior, 64, 165-181.

Bowling, N. A., Eschleman, K. J., Wang, Q., Kirkendall, C., \& Alarcon, G. (2010). A metaanalysis of the predictors and consequences of organization-based self-esteem. Journal of Occupational and Organizational Psychology, 83, 601-626.

Cavanaugh, M. A., Boswell, W. R., Roehling, M. V., \& Boudreau, J. W. (2000). An empirical examination of self-reported work stress among U.S. managers. Journal of Applied Psychology, 85, 65-74. 
Chen, Z. X., \& Aryee, S. (2007). Delegation and employee work outcomes: An examination of cultural context of mediating processes in China. Academy of Management Journal, 50, $226-238$.

Cheung, J. H., Burns, D. K., Sinclair, R. R., \& Sliter, M. (2017). Amazon Mechanical Turk in organizational psychology: An evaluation and practical recommendations. Journal of Business and Psychology, 32, 347-361.

Conger, J. A., \& Kanungo, R. N. (1988). The empowerment process: Integrating theory and practice. Academy of Management Review, 13, 471-482.

Cook, T. D., \& Campbell, D. T. (1979). Quasi-experimentation: Design and analysis issues for field settings. Skokie, IL: Rand McNally.

Crawford, E. R., LePine, J. A., \& Rich, B. L. (2010). Linking job demands and resources to employee engagement and burnout: A theoretical extension and meta-analytic test. Journal of Applied Psychology, 95, 834-848.

DeSimone, J. A., Harms, P. D., \& DeSimone, A. J. (2015). Best practice recommendations for data screening. Journal of Organizational Behavior, 36, 171-181.

Goldberg, D. P. (1972). The detection of psychiatric illness by questionnaire. London: Oxford University Press.

Goodman, J. K., Cryder, C. E., \& Cheema, A. (2013). Data collection in a flat world: The strengths and weaknesses of Mechanical Turk samples. Journal of Behavioral Decision Making, 26, 213-224.

Fodor, D. P., Antoni, C. H., Wiedemann, A. U., \& Burkert, S. B. (2014). Healthy eating at different risk levels for job stress: Testing a moderated mediation. Journal of Occupational Health Psychology, 19, 259-267. 
INTRINSIC MOTIVATION AND WORK DEMANDS 31

Fritz, C., \& Sonnentag, S. (2006). Recovery, well-being, and performance-related outcomes: The role of workload and vacation experiences. Journal of Applied Psychology, 91, 936945.

Hayes, A. F. (2013). Introduction to mediation, moderation, and conditional process analysis: A regression-based approach. New York: Guilford Press.

Hobfoll, S. E. (1988). Conservation of resources: A new attempt at conceptualizing stress. American Psychologist, 44, 513-524.

Hochwälder, J., \& Brucefors, A. B. (2005). Psychological empowerment at the workplace as a predictor of ill health. Personality and Individual Differences, 39, 1237-1248.

Hunter, E. M., \& Wu, C. (2016). Give me a better break: Choosing workday break activities to maximize resource recovery. Journal of Applied Psychology, 101, 302-311.

Ilies, R., Johnson, M. D., Judge, T. A., \& Keeney, J. (2011). A within-individual study of interpersonal conflict as a work stressor: Dispositional and situational moderators. Journal of Organizational Behavior, 32, 44-64.

Jacob, K. S., Bhugra, D., \& Mann, A. H. (1997). General Health Questionnaire-12: Psychometric properties and factor structure among Indian women living in the United Kingdom. Indian Journal of Psychiatry, 39, 196-199.

Jöreskog, K. G., \& Sörbom, D. (2006). LISREL 8.8 [computer software]. Lincolnwood, IL: Scientific Software International.

Kahn, R. L., Wolfe, D. M., Quinn, R. P., Snoek, J. D., \& Rosenthal, R. A. (1964). Organizational stress: Studies in role conflict and ambiguity. New York: Wiley. 
INTRINSIC MOTIVATION AND WORK DEMANDS 32

Karademas, E. C., Kafetsios, K., \& Sideridis, G. D. (2007). Optimism, self-efficacy and information processing of threat-and well-being-related stimuli. Stress and Health, 23, 285-294.

Kim, M., \& Beehr, T. A. (2017). Self-Efficacy and psychological ownership mediate the effects of empowering leadership on both good and bad employee behaviors. Journal of Leadership \& Organizational Studies, 24, 466-478.

King, L. A., King, D. W., Fairbank, J. A., Keane, T. M., \& Adams, G. A. (1998). Resiliencerecovery factors in post-traumatic stress disorder among female and male Vietnam veterans: Hardiness, postwar social support, and additional stressful life events. Journal of Personality and Social Psychology, 74, 420-434.

Kinicki, A. J., \& Vecchio, R. P. (1994). Influences on the quality of supervisor-subordinate relations: The role of time-pressure, organizational commitment, and locus of control. Journal of Organizational Behavior, 15, 75-82.

Lazarus, R. S., \& Folkman, S. (1984). Stress, appraisal, and coping. New York: Springer.

Lee, J. S., Joo, E. J., \& Choi, K. S. (2013). Perceived stress and self-esteem mediate the effects of work-related stress on depression. Stress and Health, 29, 75-81.

LePine, J. A., Podsakoff, N. P., \& LePine, M. A. (2005). A meta-analytic test of the challenge stressor-hindrance stressor framework: An explanation for inconsistent relationships among stressors and performance. Academy of Management Journal, 48, 764-775.

Luthans, F., Avey, J. B., Avolio, B. J., Norman, S. M., \& Combs, G. M. (2006). Psychological capital development: Toward a micro-intervention. Journal of Organizational Behavior, $27,387-393$. 
Macsinga, I., Sulea, C., Sârbescu, P., Fischmann, G., \& Dumitru, C. (2015). Engaged, committed and helpful employees: The role of psychological empowerment. The Journal of Psychology, 149, 263-276.

Mason, W., \& Suri, S. (2012). Conducting behavioral research on Amazon's Mechanical Turk. Behavior Research Methods, 44, 1-23.

Matteson, M. T. \& Ivancevich, J. M. (1987). Controlling Work Stress: Effective human resource and management strategies. Jossey-Bass: San Francisco.

Mauno, S., Kinnunen, U., \& Ruokolainen, M. (2007). Job demands and resources as antecedents of work engagement: A longitudinal study. Journal of Vocational Behavior, 70, 149-171.

May, D. R., Gilson, R. L., \& Harter, L. M. (2004). The psychological conditions of meaningfulness, safety and availability and the engagement of the human spirit at work. Journal of Occupational and Organizational Psychology, 77, 11-37.

Pierce J. L., \& Gardner, D. G. (2004). Self-esteem within the work and organizational context: A review of the organization-based self-esteem literature. Journal of Management, 30, 91622.

Pierce, J. L., Gardner, D. G., Cummings, L. L., \& Dunham, R. B. (1989). Organization-based self-esteem: Construct definition, measurement, and validation. Academy of Management Journal, 32, 622-648.

Podsakoff, N. P., LePine, J. A., \& LePine, M. A. (2007). A meta-analytic test of the challenge stressor-hindrance stressor framework: An explanation for inconsistent relationships among stressors and performance. Journal of Applied Psychology, 92, 438-454. 
Podsakoff, P. M., MacKenzie, S. B., \& Podsakoff, N. P. (2012). Sources of method bias in social science research and recommendations on how to control it. Annual Review of Psychology, 63, 539-569.

Preacher, K. J., \& Kelley, K. (2011). Effect size measures for mediation models: Quantitative strategies for communicating indirect effects. Psychological Methods, 16, 93-115.

Ramsey, S. R., Thompson, K. L., McKenzie, M., \& Rosenbaum, A. (2016). Psychological research in the internet age: The quality of web-based data. Computers in Human Behavior, 58, 354-360.

Rizzo, J.R., House, R.J., \& Lirtzman, S.I. (1970). Role Conflict and ambiguity in complex organizations. Administrative Science Quarterly, 15, 150-160.

Rubino, C., Luksyte, A., Perry, S. J., \& Volpone, S. D. (2009). How do stressors lead to burnout? The mediating role of motivation. Journal of Occupational Health Psychology, 14, 289304.

Schaufeli, W. B., \& Bakker, A. B. (2003). UWES - Utrecht Work Engagement Scale: Preliminary Manual (Version 1, November 2003). Utrecht, The Netherlands: Occupational Health Psychology Unit, Utrecht University.

Schaufeli, W. B., \& Taris, T. W. (2014). A critical review of the Job Demands-Resources Model: Implications for improving work and health. In G. F. Bauer \& O. Hämmig (Eds.), Bridging occupational, organizational and public health: A transdisciplinary approach (pp. 43-68). Dordrecht, Germany: Springer Science + Business Media. Sedikides, C., Skowronski, J., \& Gaertner, L. (2004). Self-enhancement and self-protection motivation: From the laboratory to an evolutionary context. Journal of Cultural and Evolutionary Psychology, 2, 61-79. 
Selye, H. (1974). Stress without distress. New York: J. B. Lippincott Company.

Seibert, S. E., Wang, G., \& Courtright, S. H. (2011). Antecedents and consequences of psychological and team empowerment in organizations: A meta-analytic review. Journal of Applied Psychology, 96, 981-1003.

Spector, P. E., \& Jex, S. M. (1998). Development of four self-report measures of job stressors and strain: Interpersonal conflict at work scale, organizational constraints scale, quantitative workload inventory, and physical symptoms inventory. Journal of Occupational Health Psychology, 3, 356-367.

Spreitzer, G. M. (1995). Psychological empowerment in the workplace: Dimensions, measurement, and validation. Academy of Management Journal, 38, 1442-1465.

Spreitzer, G. M., Kizilos, M. A., \& Nason, S. W. (1997). A dimensional analysis of the relationship between psychological empowerment and effectiveness satisfaction, and strain. Journal of Management, 23, 679-704.

Tadić, M., Bakker, A. B., \& Oerlemans, W. G. (2015). Challenge versus hindrance job demands and well-being: A diary study on the moderating role of job resources. Journal of Occupational and Organizational Psychology, 88, 702-725.

Thomas, K. W., \& Velthouse, B. A. (1990). Cognitive elements of empowerment: An "interpretive" model of intrinsic task motivation. Academy of Management Review, 15, 666-681.

Webster, J. R., Beehr, T. A., \& Christiansen, N. D. (2010). Toward a better understanding of the effects of hindrance and challenge stressors on work behavior. Journal of Vocational Behavior, 76, 68-77. 
Webster, J. R., Beehr, T. A., \& Love, K. (2011). Extending the challenge-hindrance model of occupational stress: The role of appraisal. Journal of Vocational Behavior, 79, 505-516.

Weigl, M., Hornung, S., Parker, S. K., Petru, R., Glaser, J., \& Angerer, P. (2010). Work engagement accumulation of task, social, personal resources: A three-wave structural equation model. Journal of Vocational Behavior, 77, 140-153.

Widmer, P. S., Semmer, N. K., Kälin, W., Jacobshagen, N., \& Meier, L.L. (2012). The ambivalence of challenge stressors: Time pressure associated with both negative and positive well-being. Journal of Vocational Behavior, 80, 422-433.

Williams, L. J., \& Anderson, S. E. (1991). Job satisfaction and organizational commitment as predictors of organizational citizenship and in-role behaviors. Journal of Management, $17,601-617$.

Witte, H. D. (1999). Job insecurity and psychological well-being: Review of the literature and exploration of some unresolved issues. European Journal of Work and Organizational Psychology, 8, 155-177.

Xanthopoulou, D., Bakker, A. B., \& Fischbach, A. (2013). Work engagement among employees facing emotional demands. Journal of Personnel Psychology, 12, 74-84.

Yang, L. Q., Spector, P. E., Gallant-Roman, M., \& Powell, J. (2012). Psychosocial precursors and physical consequences of workplace violence towards nurses: A longitudinal examination with naturally occurring groups in hospital settings. International Journal of Nursing Studies, 49, 1091-1102. 
INTRINSIC MOTIVATION AND WORK DEMANDS 37

Table 1

Means, Standard Deviations, Correlations, and Reliabilities

\begin{tabular}{|c|c|c|c|c|c|c|c|c|c|c|}
\hline 1. Workload (T1) & 3.31 & .90 & .90 & & & & & & & \\
\hline 2. Role stressors (T1) & 3.08 & 1.07 & $.38 * *$ & .91 & & & & & & \\
\hline $\begin{array}{l}\text { 4. Psychological empowerment } \\
\text { (T1 } 1 / 2)\end{array}$ & 5.18 & 1.02 & -.09 & $-.51^{* *}$ & $-.33 * *$ & $.90 / .92$ & & & & \\
\hline $\begin{array}{l}\text { 5. Organization-based } \\
\text { self-esteem (T1 } 1 / 2)\end{array}$ & 5.44 & 1.06 & -.06 & $-.55^{* *}$ & $-.38 * *$ & $.83 * *$ & $.96 / .96$ & & & \\
\hline 8. Work engagement (T2) & 4.71 & 1.08 & .06 & $-.38 * *$ & $-.22 * *$ & $.72 * *$ & $.69 * *$ & $-.44 * *$ & $.57 * *$ & .95 \\
\hline
\end{tabular}

Note. $N=336$. Workload = workload and time pressure; Role stressors = role ambiguity and role conflict; Ill Health = physical symptoms and psychological strains. Cronbachs alphas are in italics on the diagonal.

$* * p<.01$. 
INTRINSIC MOTIVATION AND WORK DEMANDS 38

Table 2

Direct and Indirect Effects of Work Stressors on Outcomes through Psychological Empowerment and Organization-Based Self-Esteem

\begin{tabular}{|c|c|c|c|c|c|c|c|c|c|}
\hline & \multirow{2}{*}{$X$} & \multirow{2}{*}{ M } & \multirow{2}{*}{$\mathrm{Y}$} & \multirow{2}{*}{$\begin{array}{c}\text { Direct effects } \\
\beta(p)\end{array}$} & \multicolumn{5}{|c|}{ Indirect effects } \\
\hline & & & & & $a b$ & $S E$ & $C I 95 \%$ & $a b_{c s}$ & $k^{2}$ \\
\hline \multirow{6}{*}{$\begin{array}{l}\text { Challenge } \\
\text { stressor }\end{array}$} & \multirow{6}{*}{ Workload } & \multirow{3}{*}{$\begin{array}{l}\text { Psychological } \\
\text { empowerment }\end{array}$} & Ill-health & $.07(.04)$ & .03 & .02 & $-.01, .07$ & .04 & .04 \\
\hline & & & OCBs & $.06(.11)$ & -.03 & .02 & $-.09, .01$ & -.04 & .05 \\
\hline & & & Work engagement & $.15(.00)$ & -.07 & .06 & $-.19, .03$ & -.06 & .10 \\
\hline & & \multirow{3}{*}{$\begin{array}{l}\text { Organization- } \\
\text { based self-esteem }\end{array}$} & Ill-health & $.08(.02)$ & .02 & .02 & $-.02, .07$ & .03 & .03 \\
\hline & & & $\mathrm{OCBs}$ & $.05(.14)$ & -.03 & .03 & $-.09, .03$ & -.03 & .04 \\
\hline & & & Work engagement & $.13(.01)$ & -.05 & .06 & $-.17, .06$ & -.04 & .06 \\
\hline \multirow{12}{*}{$\begin{array}{l}\text { Hindrance } \\
\text { stressors }\end{array}$} & \multirow{6}{*}{$\begin{array}{c}\text { Role } \\
\text { stressors }\end{array}$} & \multirow{3}{*}{$\begin{array}{l}\text { Psychological } \\
\text { empowerment }\end{array}$} & Ill-health & $.15(.00)$ & .10 & .02 & $.06, .14$ & .17 & .16 \\
\hline & & & OCBs & $-.06(.10)$ & -.15 & .03 & $-.21,-.10$ & -.23 & .21 \\
\hline & & & Work engagement & $-.02(.69)$ & -.37 & .05 & $-.46,-.28$ & -.36 & .40 \\
\hline & & \multirow{3}{*}{$\begin{array}{l}\text { Organization- } \\
\text { based self-esteem }\end{array}$} & Ill-health & $.14(.00)$ & .11 & .02 & $.07, .15$ & .19 & .18 \\
\hline & & & OCBs & $-.02(.59)$ & -.19 & .03 & $-.26,-.13$ & -.29 & .26 \\
\hline & & & Work engagement & $-.01(.89)$ & -.38 & .05 & $-.47,-.29$ & -.37 & .36 \\
\hline & \multirow{6}{*}{$\begin{array}{l}\text { Interpersonal } \\
\text { conflict }\end{array}$} & \multirow{3}{*}{$\begin{array}{l}\text { Psychological } \\
\text { empowerment }\end{array}$} & Ill-health & $.21(.00)$ & .11 & .02 & $.06, .16$ & .12 & .13 \\
\hline & & & $\mathrm{OCBs}$ & $-.02(.65)$ & -.15 & .03 & $-.22,-.10$ & -.16 & .16 \\
\hline & & & Work engagement & $.03(.61)$ & -.35 & .06 & $-.48,-.23$ & -.24 & .28 \\
\hline & & \multirow{3}{*}{$\begin{array}{l}\text { Organization- } \\
\text { based self-esteem }\end{array}$} & Ill-health & $.19(.00)$ & .13 & .02 & $.08, .17$ & .15 & .15 \\
\hline & & & OCBs & $.03(.56)$ & -.20 & .04 & $-.28,-.13$ & -.21 & .21 \\
\hline & & & Work engagement & $.07(.24)$ & -.39 & .07 & $-.53,-.26$ & -.27 & .30 \\
\hline
\end{tabular}

Note. $\mathrm{X}=$ a predictor; $\mathrm{M}=$ a mediator; $\mathrm{Y}=$ an outcome. $\beta=c^{\prime}$ (direct effect). $a b=$ estimated indirect effect. $S E=$ bootstrap standard error. $a b, S E$, and $C I 95 \%$ were obtained from 10000 bootstrap samples. $a b_{c s}=$ completely standardized indirect effect. $k^{2}=$ indirect effect/ maximum possible mediation. 